Second Annual Meeting of the American Psychopathological Association, at Baltimore, May 10, 1911.

The President, Dr. Morton Prince, presiding.

1. The President's address: The Mechanism of Recurrent Psychopathic States, with Spectal ReFERENCE to ANXiety States.

2. Symposium on the Pathogenesis of Morbid Anxiety.

by Dr. Ernest Jones, Toronto.

Dr. Boris Sidis, Boston.

Dr. John E. Donley, Providence.

\title{
DISCUSSION ON THE SYMPOSIUM
}

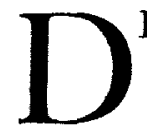

R. J. J. PUTNAM, Boston: I take pleasure in assenting to practically all of what Dr. Prince has said, except that I believe he does not go far enough in certain directions. The mechanism that he suggests for these states seems to be a reasonable one, though it is doubtful whether it is an advantage to use the term "neurograms," because it seems to me that this creates a difficulty where such difficulty might be avoided. We have to deal with these cases by psychological methods; and it is better to keep, so far as we can, on the psychological basis in conceiving them. If we once begin with "neurograms," it is hard to know where we can leave off. If we can get along without the use of the physical nomenclature, it seems advisable for us to do so. Dr. Prince had a good deal to say about the "terrifying ideas pointing back to subconscious experiences." That is one point on which I agree with him, but I think that in certain circumstances, if he should use the psycho-analytic method with thoroughness in studying his patients' cases, he would discover even more subconscious experiences than he thinks. I also accept his view that an emotional state may exist independently of the ideas that gave rise to it. This conception seems practically equivalent to that of which Freud has made so much use and for which he has adopted the term "flottievende Angst." The term, "habit neurosis," is an attractive one, and we have all employed it, but the question is whether 
instead of saying "habit neurosis," we could not penetrate to a more definite etiology in each case. Dr. Prince refers to the concentration of a general sense of apprehension in the form of "single fears." That, too, I would agree with; but there it seems to me that the single fear probably stands, as Dr. Jones has pointed out, as a representative and substitute for many possible fears. The patient agrees with himself, as it were, to let one fear stand for all the rest.

Dr. Prince speaks of the unconscious mechanism as only working sometimes. I should rather put the matter in another form, as, namely, by assuming that these elaborate processes go on in the unconscious mind all the time, but only become manifest from time to time as especially in dreams.

With regard to Dr. Jones's paper, I have only to say that I think we psychoanalysts have endeavored too much to refer the explanation of all these phenomena to the genetic principle. In doing that, we range ourselves exclusively with the observers of the natural-science school, who are, as I believe, entirely too deterministic. If we do not believe that there is anything except our genesis in the earthly sense to deal with, this may be true; but I do not think that this is all that we have to deal with. In other words, I think man presents himself to us as an individual exposed to influences of two sorts. $\mathrm{He}$ is not only working instinctively away from a condition, but also consciously towards a goal, and I think that this fact has not been adequately dealt with.

Regarding Dr. Donley's paper, I would simply say that without his cases his argument seems to me to be of no weight. I believe that the introspective method, if carried far enough to involve philosophic introspection, is practically the only method in our hands; and I do not see why it is not sufficient. Many of us have taken cases as they have come to us, and have found that in essential respects Freud was right about them. If there are other cases in which it can be proved that the principles he proposes are not right, we should, of course, like to hear about them and have the opportunity to examine the patients for ourselves. It is hardly fair to speak of a selection of cases, because this 
selection has not been made by persons working by psychoanalytic methods. They have taken every case.

DR. William A. White, Washington, D.C.: A thought has occurred to me as being pertinent to the present discussion. It would seem that Dr. Jones's and Dr. Sidis's papers might be considered together. Dr. Jones refers the etiology of morbid anxiety to the sexual instinct, and Dr. Sidis to the instinct of race preservation. It occurs to me that there is too little recognition of the relation of these two fundamental instincts to each other. The instinct for the preservation of the race is so closely related to the sexual instinct that the latter may be conceived to be a modality of the former. The instinct of reproduction has as its object to continue the existence of the individual in that of the children. Perhaps the two views from this standpoint might receive some sort of correlation. This thesis could be supported at considerable length, and is worth more consideration.

Dr. Tom A. Williams, Washington, D. C.: The phylogenetic considerations just adduced by Dr. White could be discussed at great length, but I hardly think that such a discussion would be profitable at the present stage of our knowledge, because differences of opinion largely arise from differences in appreciation of the data.

Dr. Jones and Dr. Sidis refrained from presenting casuistics, for reasons that we can understand. At the symposium on Dreams, during the last annual meeting of the association, that was thoroughly done; and the cases cited are in the literature and are accessible to every one. This is not the place to discuss this question, then.

I have heard here nothing to shake the opinion that angoisse is nosologically best regarded as one of the most constant features of Janet's psychasthenia. But I do not wish further to affirm, only to question. Therefore, I ask Dr. Jones why he has made an appeal to esoteric experience, for that is a method which is apt to tend to suppress the inquiry of others, and to make them accede to the authority of him who employs the method. It is that of the supernaturalists and the mystics, who say, "Experience the mystical phase and you will understand." I wish to 
protest against the use of that method of appeal in scientific study and discussion.

Again, regarding the allegations of the superlative success of the Freudian method, to which Dr. Putnam has referred, it is admitted that the method has been more successful in removing symptoms than was one of those formerly much used, viz., direct suggestion after crude analysis, for, of course, the removal of ideas by making substitutions is made possible only by psychological findings. Cases of, e.g., Janet, however, treated by somewhat naive substitutions often relapsed; but those of Freud did not perhaps so frequently. Therefore, we may assume that the Freudian method is more thorough than the old crude suggestive therapeutics; but this is not to say that good results are an exclusive appurtenance of the Freudian method. Many of us who do not accept the views of Freud are more thorough and more profound in analysis than were the old suggestive therapeutists, perhaps no less so than Freud. Dr. Prince has made that clear. Data exist which indicate that Freudian psycho-analysis needs supplement by deliberate re-education and training of control.

Another affirmation of Dr. Jones, that there is a difference between morbid and normal fear, is, I believe, an error as regards any essential factor; for the physical symptoms occur as markedly in normal fear, in certain individuals, as they do in so-called pathological fear. There is, however, this difference: the morbid fear-reaction is apt to be more prolonged; because it is the tendency of the normal fearreaction to disappear rapidly as soon as a realization of the non-existence of the terrifying thing is conceived, whereas the morbid fear-reaction is perpetuated, as Dr. Putnam has stated, by a mnesic affect due to an idea, which is always present, as explained in my paper on "Traumatic Neuroses," in THE JOURNAL OF ABNORMAL PSYCHOLOGY, last year. Hence, morbid fear is apt to be of longer duration than the ordnary normal fears.

Then, with regard to the distinction drawn as to the disproportion of the intensity of an emotion to the apparent provoking cause, is not this alleged "disproportionateness" merely the viewpoint of an observer, who may really have 
few criteria for correct judgment until his superficial estimate is corrected by a knowledge of the facts in the patient's psyche?

The patient, however, has a special point of view; and there is no disproportion from his point of view, which it is our business to find out. Therefore, that is not an essential distinction as to the morbidity of any given fear. It has been said here of fear that our standard with regard to normality is too low. What, then, is the normal standard? It seems to me that this argument is only a preconceived notion and demands proof.

Now, with regard to pure Angst, I am sorry to say that Dr. Jones, in his discussion, has invoked and sustained his thesis on the analysis of pure Angst; but later has cited largely from a case of definite individual phobia to support his contentions. It seems very difficult to find data in support of the existence of pure Angst, but supposing that such could be found, could the occurrence of a few cases justify us in giving it a special category in this argument, when we know that it is so often as marked a feature of "psychasthenia"? Even though the Angst symptom may be found alone occasionally, we must remember that there are a few cases in which there is an apparent "manie" ideational symptom, without any emotional accompaniment whatever, yet no one now believes that we have the right to separate from psychasthenia the cases in which the "manie" appears to be alone. We remember that "manie" is a symptom in a much larger syndrome, in which Angst and other symptoms are also to be found in nearly all cases.

Very often, however, it is true that the phobias that a patient manifests are seemingly merely the embodiments of a general state of Angst, aroused in another way. Indeed, what Dr. Prince has called the "auto-suggestive mechanism" either creates the anxiety of the patient or reinforces it through the direct attempt to overcome emotion. Emotion fought against is really reinforced. Emotion must be conquered by overcoming the genetic, factor which is often ideation and not emotion at all.

It has been denied in this contribution that physical factors have any influence in the creation of the Angst syn- 
drome. In what way, then, is the greater tendency to the formation of phobias with angoisse in such states as Graves's disease, physical atony, uremia, and surgical shock explained by persons so contending? We all know how easily the fears of the normal individual can be excited in these states, and can then become morbid. Dr. Prince has also touched upon that question in speaking of the genesis of the anxiety state of asthenia. Have we not aroused confusion by judging psychical cases by cases in which the basic factor was a physical one? Should we not be careful before generalizing to exclude these cases altogether in the investigation of psychogenetic conditions?

Now as to pathogenesis, it is true that cases arise on the basis of the early formation of an easily excited disgust; but this is not necessarily sexual. It may be excited by the temptation to sin of any kind, but the main factor in such cases is fear and shame, on account of the indulgence, not because the indulgence was sexual, but because it was one that had been created into a very severe disgust-complex by extraneous influences of sociological order, i.e., an induced affect.

DR. I. H. Coriat, Boston: It appears to me that in the discussion of the anxiety neuroses, confusion has arisen from attributing the Angst attacks, on the one hand, to a purely sexual basis; and, on the other, to purely psychogenetic factors. There are other emotions as primitive and instinctive as the sexual, and the typical attack called the anxiety attack is not always due to repression of sexual ideas or motives. The disgust-complex, from which a number of these attacks arise, may also arise on other than a sexual basis. These abnormal fears, of which, to my mind, the anxiety neurosis is simply a reaction, may be due to the dissociating effect of any emotional shock or any series of emotional shocks. These emotional experiences need not become unconscious or subconscious. The emotional shocks may remain clearly in the consciousness of the patients. I have had that fact illustrated in two or three cases, in which a series of emotional shocks clearly remembered by the patient were followed by typical Angst attacks, the patient remembering the origin of the attacks and could clearly trace the cause of each individual attack. 
The chief criticism of the Freudian school of psychology seems to be that we do not carry our analyses sufficiently far, or otherwise we would find a sexual etiology for the psycho-neurosis. In other words, if we carry our analyses and all the data of the dreams or the life of the individual back far enough, we must invariably find the repressions in the etiology claimed by Freud. I do not think that this is so, because I have reports of several psycho-analyses that only partially bear out Freud in this. In the last number of the Journal of Abnormal Psychology you will find a paper by me containing a very minute psycho-analysis of a case of hysteria, which, to my mind, was as complete as anything could possibly be made, even by a member of the Freudian School. Yet this analysis only partially bears out the Freudian theory, although I was dealing with a highly intelligent subject, who thoroughly co-operated with me. After two years' work on one case, if we cannot get at subconscious complexes of a sexual origin through the method of Freud, I do not see how much farther the analysis can be carried. I also brought out in that paper the fact that complete psycho-analysis did not cure the condition. The change from repression to free expression has only a partial therapeutic value, particularly if an automatic process has been formed. The getting at the suppressed material does not always cure the condition, if an automatism has taken place. We must break up this automatic process by some other technical method.

Anxiety states may be associated also with purely physical diseases. I have seen states of typical anxiety aroused during paroxysmal tachycardia, in the tachycardia of exophthalmic goiter, and in the cases that resembled angina pectoris, but were probably of a pseudo-angina variety.

I have had under my observation a number of cases of anxiety neurosis, on all of which I have made as complete a psycho-analysis as I should care to do. In some of these cases I found a definite sexual etiology; and in others, in which the psycho-analysis was most complete, I could not find such an etiology.

Dr. E. E. Southard, Cambridge: I should like to set down three adjectives which may serve to distinguish three 
types of psychopathological process:

1. Vestigial.

2. Residual.

3. Neoplastic.

Under vestigial processes we may classify various mental phenomena of phylogenetic or racial origin, such as sex and hunger feelings, and the like.

Under residual processes appear ontogenetic ideas and feelings, based on occurrences within the life of the individual, or the neurograms (to adopt Prince's phrase) of a particular acquired experience. Here would belong many of the phenomena of angstneurosen being considered to-day, colored though they may be with vestigial elements too.

The third group of processes which I term (for want of a better term) neoplastic processes I regard as incidental to certain neural processes, but by hypothesis not running back to racial vestiges or to residua of infantile or other early experience. May not certain contents of the mind be newly formed in the course, e.g., of brain disease, and, however colored or overlaid by vestigial or residual experiences remembered by the subject, be essentially independent of these? Consider the feelings attributed to an amputated foot! These feelings are attributed to a periphery that does not exist, though they are actually due to goings-on in the stump. Transfer this idea to the central nervous system, and it can be readily imagined how new neurograms may be, as it were, manufactured by disease. Yet these novel configurations of nerve impulse would be interpreted in terms of all available neurograms, whether vestigial or residual, and given some sort of meaning. In my own mind I have been terming the stimuli of central origin that give rise to such novel morbid experiences quasi-peripheral stimuli. The stump stimuli of the amputation cases refer to the lost foot as a quasi-periphery and are so unfailingly referred by the reacting nervous system. Theodor Meynert long ago offered a simple example of a fixed posture adopted, as Meynert thought, in the vain endeavor to secure muscle sensations from a certain region which had been excluded by reason of a lesion of the thalamus. May not disease graft on certain phenomena of a compulsive character, 
which, however closely they may seem to correspond with significant historical facts in the victim's experience, are, strictly speaking, quite independent thereof?

Dr. Adolf Meyer, Baltimore: Not having received the papers that were offered, and having heard only the controversial part of the discussion, I limit myself to one very urgent appeal essential in the situation, viz., that we must get more accurate casuistic or experimental material as a foundation for any discussion whatever. In order to avoid our getting into endless difficulties over generalities we need simple and accurate methods of reporting and of promulgating our facts, and the possibility of having these controlled by other observers as freely as possible. The question of how to record neuroses and make them readable within the span of time that is allotted to most of us, and how to bring the actual cases under the criticism and under the observation of several individuals, is an extremely difficult one; but we have to try to make it possible for limited circles and groups of men at least - much more freely than we have been doing.

Dr. Southard's remark reminds me in some respects of the claims of those who maintain that the hallucination theory is practically exhausted by an emphasis of the peripheral irritations. We must not overlook the rôle of the wear and repair of the structures themselves in the process of activity, and such facts as Crile's observations in fear and the like. There is absolutely no doubt that we have more than merely psychical relations to consider in these cases. We also have a lowering of the resistiveness and balance of the mechanisms and structures that play a rôle. For instance, a heart neurosis will ultimately lead to a heart condition that is set off mainly from there being a lowering of the ease of regulation of the submental mechanisms; and, considering that, it seems to me that to view the matter purely from the psychical point of view, without considering that the mental functions are integrations of submental functions, would probably lead to endless quibbles. There is no doubt that the psychical connections are most fundamental, as they are the original links of the emotion; but other conditions have to be taken into consideration along 
the line suggested by Dr. Southard or along that of Dr. Crile.

Dr. Putnam: I should like to say a word regarding Dr. Southard's and Dr. Meyer's remarks. I sympathize with what Dr. Southard has said, and do not want my remark to be understood as opposed to these ideas. The reason that many of us have insisted so strongly on the psychical aspect of these matters is not that we deny that a person brings into the world the vestigial tendencies which one could often express best in physiological terms; it is rather that we wish to emphasize those elements in any given case with which we can deal most easily therapeutically. If there are causes that have been operative since birth, and that one has, therefore, a better chance to remove, these need to be especially considered.

Dr. Waterman, Boston: I should like to cite two cases as illustrative of what seem to me to be definite exceptions to the states of Angst-neurosis that can be traced back to sexual disturbances.

No doubt there is a large number of cases in which sexual disturbance can be shown to be the cause of Angstneurosis, or at least a strong etiological factor in these conditions.

Recently a patient came under my observation who is more than eighty years old, and of very strong character. $\mathrm{He}$ is a physician, was an army surgeon in the Civil War, and has had quite a varied career, involving exposure to many kinds of danger. He said when he came to me, that he had just been undergoing an absolutely new experience. He had never before been afraid in his life, and had not known what fear or anxiety was, but for the three nights previous he had been filled with a sense of overwhelming fear. It was more distressing than anything he had ever experienced, and he could not imagine what caused it. Examination showed that he had the following physical signs: He had had myocarditis for some time, with atheromatous arteries. More recently he had contracted an attack of influenza, with a cough, the sputum showing the presence of influenza bacilli. This coughing had thrown an extra strain on his heart, resulting in a considerable enlargement of that organ, associated with irregularity of the pulse and an almost 
characteristic Cheyne-Stokes respiration, except that there were no periods of apnea. He had the physiological manifestations of fear. But the interesting point is that the sweating and the rapidity of the heart beats and the rapid respirations were associated with psychological manifestations, and he suffered from intense anxiety and mental distress, a condition which he had never experienced previously. There was a physical cause for this condition, and to me this affords a pretty illustration of the JamesLange theory.

I should also like to cite the case of a fireman who was noted in the fire department of the city of Boston as being a most reckless and fearless driver. He said that he never remembered having been afraid in his life until one day when driving to a fire his engine collided with an electric car, and he was thrown out and hurt. He was unconscious for a while, and it was a week or ten days before he recovered from his injuries. The first day that he went out the sight of an electric car brought on a sense of fear, associated with an anxious expression of the face, a rapid pulse, and sweating. These attacks continued to come with greater and greater frequency, so that he was unable to go about.

It seems to me that cases of this sort must come under another category. It is true that the theory of a subsoil of sexual disturbance may be brought forward as paving the way for such anxiety states, according to Freudian principles, yet it seems to me that we must accept these two groups of cases, namely, those with an organic basis, and those commonly classified as traumatic neuroses, as being based on different etiological principles.

DR. Jones: There are a number of questions raised that I shall not say anything about, because they do not seem relevant to the subject of the symposium. Dr. Coriat and Dr. Williams talked of the relative effects of psycho-analytic treatment. It seems to me that this is an entirely different subject. Dr. Williams put a number of questions directly to me, I think, which I should answer. He said that it had been maintained in this discussion that physical factors cannot play a rôle in the causation of anxiety states. Now one of the main points that I tried to bring 
out is that anxiety states are invariably due to physical factors, and nothing else. I also laid considerable stress on the fact that this point has nothing at all to do with psycho-analysis, but can be investigated by any one, whether he has ever heard of psycho-analysis or not; and it has been by a number of such observers. It is a matter of direct, simple clinical observation. Similarly, Dr. Williams said that I have repeatedly referred to or made use of the argument that these matters depend upon an esoteric method. Well, that is really answered by my last remark. I think that I need hardly say that I have never made any such remark, either in those terms or in terms that would bear that construction. In regard to the "esoteric method," is not that just the same as saying that if you take the trouble to learn Italian you can read Dante in the original? Any one can learn either Italian or psycho-analysis. Neither is very difficult, but I wish to separate that from the question of the anxiety state, which is a matter of simple clinical observation. Dr. Williams brought up the subject of the nosological position of the anxiety neurosis, and said that he did not think it fair to separate from the broader group of psychasthenia the cases with anxiety on account of their small number. In point of fact, those of anxiety do not comprise a small number. Personally, I believe that it is the commonest disease in all medicine, so that those belonging to it could hardly be called a few cases.

The two cases cited by Dr. Waterman are, of course, susceptible of a very simple explanation, which was given many years ago by Freud himself. Such cases are very familiar to any one who has any experience in psychopathology. There is no dispute on the question of facts; it is merely a matter of interpretation. Freud laid stress on the fact that both organic changes, such as heart disease, and the other mental causes, such as fright, are important factors in the evocation of the neurosis of this type; but stated that they will never operate unless the specific cause is also present. That is a matter of simple observation. Bring forward some cases in which this is absent, and then disprove Freud's view. We have heard nothing about the sexual life of these patients. 
Dr. Donley has made a number of remarks about the "nebulous reasoning" of those whom he politely calls the "disciples" of Freud. Some of these remarks are open to comment. For instance, in referring to Freudians, he said that it is a dependable sign of scientific immaturity to accept forthwith every new opinion, doctrine, or hypothesis promulgated even by authority. Has Dr. Donley ever heard of any one who has accepted Freud's views in that way? I have not. They have all gone through a period of considerable doubt and objection. I have yet to hear of any one who has forthwith accepted Freud's views. In two or three places Dr. Donley refers to Dr. Freud's "recent" suggestions. These were made nearly twenty years ago. Dr. Putnam was aware of these views for many years before accepting them.

One of the points that Dr. Donley brings forward as a criticism is based only on Freud's first paper on the subject, and he does not quote anything from the papers of Freud in which the subject is dealt with much more fully. In the original paper, Freud wrote tentatively, cautiously, and fairly. He said that in the majority of cases he had found a particular variety of sexual etiology, but that in a few cases he had not. He said that as nothing was known of the etiology of these, he ventured to set them aside for the purpose of that brief communication. He did not say that these were not cases of anxiety neurosis, as Dr. Donley maintains. The argument that Dr. Donley brings forward may be explained by this instance: When Fournier, in the early eighties, said that in a great many cases of tabes and other cases of general paralysis he had found evidence of syphilis, he did not say that the other cases, without this evidence, were not cases of general paralysis. Neither did Freudsay that the other cases were not anxiety neurosis. Both said that they had found this etiology in many cases, and thought it probable that further investigations would reveal it in the rest - as in both instances has proved true. Dr. Donley says: "There is here no more justification in logic than there would be were we first to divide fractures into those caused by falling on the sidewalk and those caused by automobiles, and then to attribute the name fractures only to 
those having the latter etiology." As to that, all that I have to say is that if there were no criticism of Freud's work more difficult to meet than that, we should be doing very well.

In the anxiety neurosis a particular variety of sexual disturbance (not sexual excess, as Dr. Sidis wrote) is invariably present. If this view is not true, why not disprove it by bringing forward cases in which this etiology is not present? We say that it will not arise with a normal sexual life. If it will, it is easy to prove it. No one has brought forward cases of that kind, however.

Dr. Prince: Perhaps I may be permitted, as the subject of my address is so intimately connected with that of the Symposium, also to take part in the discussion. In what I have to say I would like to accentuate the difference between the position taken by Dr. Jones and that held by some others, especially myself. There is a difference of opinion regarding what we are trying to explain, regarding the nature of the clinical syndrome for which we are trying to find a psychogenetic or etiological factor. The position held by Dr. Jones is that these anxiety neuroses are to be classed as something distinct by themselves, as different from the phobia neurosis; that the anxiety neurosis is very different from the ordinary fear psychosis. Some of us hold a different opinion; and so long as there is a difference of opinion regarding this fact, we must expect differences of opinion as to the cause.

In my opinion an attack of anxiety neurosis is nothing more than a variant of the fear psychosis; it is an incomplete attack. Perhaps I may be permitted to repeat that in 1896, one year after Freud separated his anxiety neurosis from other states, and without having seen his work, I described the fear neurosis in contradistinction to the fear psychosis. The syndrome of the fear neurosis seems to me to be substantially the same as that of anxiety neurosis. It consists of the physiological manifestations of fear without specific ideas of fear. It seemed to me, then, to be a paradoxical phenomenon in that $I$ was inclined to think that there was no psychical element of anxiety present, but in this I may have been wrong and misled by the denials of the patients. I saw, however, no reason for believing it to be in any way essentially different in mechanism from the 
phobia psychosis. It was simply the physical manifestation of fear, without the fear itself.

It was possible in the cases described to find in the early life of the patients a history of specific anxiety ideas which were originally associated with the physical manifestations, but which afterwards, for reasons which I will not go into, had dropped out of the attack. There remained, however, always anxiety in the form of apprehension of an attack, which apprehension was often sufficient alone to induce an attack.

Now psychopathological experiments have shown that in certain anxiety states the specific ideas which give rise to anxiety may be entirely subconscious, and the subject not aware of them. Therefore, in any anxiety state it is not possible to exclude the presence of specific coconscious ideas without an investigation of the subconscious, and perhaps not even then. In illustration of what I mean, suppose we take a case of multiple personality in which one personality exhibits intense fear or anxiety without knowing why. In such a case you may find that there have been very specific ideas relating to particular objects and which were previously entertained by one of the other personalities. On change of personality taking place these specific ideas remained subconscious while the emotion welled up as indefinable anxiety in the altered personality. Janet, amongst others, has shown that in hysterics who exhibit anxious states very specific ideas of which the subject is not aware may persist coconsciously. Such patients then exhibit anxiety with its physiological manifestations without knowing why. On such and other grounds I personally cannot see any reason for differentiating in principle the anxiety neurosis from the phobia psychosis. I may be wrong in this view, but if I am right we should look for the same mechanism in the phobia, and vice versa. In such discussions, therefore, it is important to keep in mind the fact that there is difference of opinion regarding the nature of the anxiety neurosis.

To take another point, Dr. Jones speaks of morbid fear as being characterized by a "disproportion between the intensity of the emotion and the occasion of its occurrence," 
and in another place he says, "as the outburst of anxiety frequently takes place as a reaction to trivial occasions, which in the normal give rise to little or no anxiety, and also occurs quite spontaneously, independently of any ascertainable external cause, it follows that the external agents (including here also ideas of danger, etc.) cannot be regarded as the true cause of the anxiety; but at most as evoking factors."

Now in my experience, and I have examined the details of numerous attacks with great minuteness, I have been able to find in every case an exciting cause for the attack. In such studies I have always been able to bring out that the attack had been brought on by some particular excitant by some remark overheard by the patient, some perception of or thought suggested by the environment, etc. Such a stimulant was always found to be the exciting cause of the attack. Such an exciting cause is apt to be, and perhaps generally is, forgotten by the patient. The same is true of some of the symptoms which constitute the attack. These are forgotten perhaps in consequence of the distracting effect of the great emotional disturbances. However that may be, in distraction or light hypnosis the memory of them can be recovered.

Then, too, in every case I have always found that one of the factors in producing an attack is the antecedent apprehension of the attack. This is always present, so much so that the mere apprehension itself will act as an exciting cause, and is sufficient to bring the attack to pass. From my point of view, it acts just as suggestion in hypnosis does in producing post-hypnotic phenomena. You suggest to a person in hypnosis that he will feel so and so under such and such circumstances. The circumstances arise and, acting as a stimulant, arouse these suggested phenomena. The apprehension that an attack will occur under given circumstances is an expectation and auto-suggestion that the given circumstances will produce an attack. The patient expects the attacks because having had them under certain circumstances he believes that another will take place under similar conditions. These conditions arise, and an attack is developed. Inasmuch as a number of 
these symptoms are very unpleasant, such as intense anxiety, palpitation of the heart, etc., the patient naturally becomes afraid of their repetition, and he is constantly apprehensive of their recurrence.

As to the "disproportion between the intensity of the emotion and the occasion of its recurrence" I may say that it is this element of anticipatory apprehension which largely determines whether a given occasion is an adequate cause of an attack or not, whether an occasion which is inadequate for one person may be adequate for another. The anticipation converts an inadequate into an adequate stimulus.

To take a simple illustration: walking down the street or across open places may mean nothing to one person but much to another; it is not sufficient to precipitate an attack of phobia in the ordinary person, but if a person has a real or imaginary heart disease, or is liable to faint and in imagination conjures up in anticipation the dangers of collapse in the street or open places from heart disease or from fainting with expected death, without possibility of help, the proposed excursion when undertaken becomes an adequate cause of an attack. Further, if other attacks have occurred in such places the knowledge of the fact awakens an anxious expectation. It further tends to convert an ordinary innocuous occasion into a nocuous one. The attacks have occurred, and it is feared and expected that they will occur again. Hence a given occasion may mean much to one person and little to another, and a sufficiently exciting cause in one person may not be in another. It is impossible to say, therefore, what is adequate as a stimulus without a thorough knowledge of all antecedent phases of the mind.

As opposed to this conception of anxiety states, Dr. Jones's contention is that in their mechanism as distinct from that of the phobias, a sexual excitation being deflected from its aim is converted into a morbid anxiety. Without entering into the question as to whether he is right or wrong I want to insist that this is a matter of interpretation. Even so is it a matter of interpretation whether the very case he cites (p. 103) as an anxiety neurosis is not a phobia. 
To my way of thinking it is as neat a case of phobia, with a distinct fixed specific fear as one wishes to see. This patient, according to the account given, had had specific sexual experiences, and against the temptation to return to these she had continuously struggled for years. With intense shame and remorse she had equally intense fear that she would succumb to the temptations. The patient's own interpretation of her anxiety symptoms seems to me to have been entirely correct. It was fear with very specific fixed ideas with reference to a specific act. These specific ideas apparently occurred over and over again, accompanied by fear and its somatic manifestations. It seems to me, therefore, that this very case cited in favor of the sexual hypothesis may well be regarded as an ordinary phobia, and in any event it is a matter of interpretation.

"With a partly correct intuition," he says, "she interpreted her anxiety symptoms as a dread against once more succumbing to the temptation." How does that differ from the specific fear of a person who thinks, "I am afraid that if I go to the window I shall fall out?" Your patient thinks, "What an awful thing it would be if I should do a thing like that; I am afraid!"

In all psychoneuroses we find, I believe, that antecedent experiences have led up to them, have prepared the ground for them, and form logical reasons for the patient's specific fears; but it is always a matter of interpretation. On page 95, Dr. Jones says, "Morbid fears are the external expression of internal wishes. It is plain that every fear is but the obverse of a wish, e.g., a wish that the feared event may not happen." While it is perfectly true that every fear is the obverse of a wish, it is another thing to say that it is always the expression of a wish, meaning that there is always a present wish, and it gives rise to the fear. This is not obvious, and is a matter of interpretation, and that which he adopts seems to me to be at variance with what we know of the mechanism of instincts. If we believe that fear is a biological instinct, we must study it from the same point of view that we do all instincts, that is, as a reaction. Every instinct is a reaction to the environment or to the internal processes of the organism, and there are many kinds of 
mental experiences to which fear may be a reaction. The question in every case is, to what stimulus is the fear or other instinct a reaction? To say that the fear in phobias is always the reaction to a wish because the latter is the obverse of fear does not seem to me to follow. This would imply that there was always a specific wish present, and that it is converted, so to speak, into fear.

So I think the case mentioned by Dr. Jones on page 95 is open to several other interpretations which can be plausibly constructed from our knowledge of human nature. For instance: it is said that the patient had once thought that if she did not have the child she might get a divorce and remarry. Now assuming that this is equivalent to a wish a debatable assumption - it is highly probable that this guilty wish was momentary, and gave rise to the horrible thought, "Suppose the child should die," etc. The horror and shame of such a thought is a trauma, which tends to leave a lasting impression. This thought became a phobia, and the momentary "wish" might well have then ceased to be a factor. Why the thought became a recurrent state, a phobia, must be sought in antecedent formative experiences. Such formative influences might be the guilty consciousness that her contemplated act would be socially condemned, and her recognition of her own weakness, and that she would yield to the temptation if her child should die. Hence her apparently unreasonable fear lest her child should die and she should succumb to the temptation. The mental conditions in such a situation are complex and difficult to state in a condensed form, and still more so to elicit from the confessions of the patient. The interpretation I suggest is, of course, hypothetical, but it is a possibility that needs to be investigated.

Still, I admit that if it could be shown that there was a continuously existing wish (conscious or subconscious) for the child's death, this wish might be a factor in keeping alive the horrifying thought of the child's death, and the phobia might, in that case, be an indirect reaction to the wish. In every case the question is of the actual factors involved, and the interpretation of them. I see no reason to assume, however, that there must be a wish in every case, 
nor do I think that the analysis of cases bears this out. On the contrary, I think such analyses show that phobias are more often due to other kinds of antecedent experiences, which may be beliefs, attitudes of mind, etc.

DR. Jones: I wish to speak of only one point that Dr. Prince has raised, in which we agree more completely than he appears to think. Every one would agree with Dr. Prince in denying that a wish could be converted into a fear. No one would hold that it could. Certainly, I do not. I regard the morbid fear as the biological instinct itself, but think that it attains an exaggeration of its morbidity as a reaction to the wish. The wish is not converted into it, but it is itself the reaction to the wish.

Dr. Donley: When I said "scientific immaturity" I had no intention whatever to refer it to the followers of Freud. I meant no more than this, namely, that before we accept the dictum that anxiety states are practically all of sexual etiology, it may be, perhaps, not amiss to examine the grounds upon which such a doctrine is based. Reduced to its lowest terms it seems to me that the question comes to this: what are we willing to accept as an explanation for a given fact or set of facts? How far back must we push our analysis before we shall consider it satisfactory? If we pursue psycho-analysis sufficiently far I think that we can find sexual factors in most every case. But the problem is, as I see it, must we go to this extreme in every instance? Let me illustrate my meaning by reference to a case of anxiety in which, judged by the results of treatment, the sexual element was not important. Dr. Putnam will remember the patient very well, for he saw him with me. This patient, a young man, was riding on the train from Boston to Providence. He was much fatigued after a hard day's work. When the train arrived at a point midway between the two cities it ran with great speed over a number of switches. Here he had a sudden feeling of faintness and got into a panic of fear because he thought he was going to die. This experience was the point of departure for a large number of fears, one of which was inability to travel upon a train without an immediate crisis of anxiety with all its physiological accompaniments. His occupation of traveling 
salesman he had to give up. The treatment as well as the diagnosis has been conducted without reference to sexual etiology, and, fortunately, with success, so far as the fears are concerned. Now I suppose in a case of this sort it would be easy enough to say that the full etiology was not laid bare, but however that may be, the patient has, by methodical re-education, acquired the ability to go upon a train without panic. If your psychological principles lead you to maintain that it is necessary to search for some sexual factor, that is one thing; but if you are willing to accept what seems in practice to be most obviously the operative cause, that is quite another thing. In a word, the problem reduces itself to the question of what sort of an explanation will satisfy us. It is not a difficult matter to construct an explanation which itself is quite as much in need of explanation as the thing it is put forward to explain. May we not in our interpretations read into patients things that in reality are not there?

(The discussion of the following papers will appear later as they are published.)

3. Dr. J. J. Putnam (Boston): The Need of Greater Emphasis on the Constructive Side of PsychoAnalytic Work.

4. Dr. E. W. Taylor (Boston): The Possibilities of a Modified Psycho-Analysis.

5. Dr. A. A. Brill (New York): The Mechanism of Compulsion Neuroses.

6. Dr. I. H. Coriat (Boston): A Theory of Sleep.

7. Dr. Tom A. Williams (Washington): The PsychoGenesis of Writer's Cramp, and other Occupation Neuroses. 